JOURNAL OF SYNCHROTRON RADIATION

ISSN 1600-5775

Received 6 June 2018

Accepted 4 August 2018

Edited by G. Grübel, HASYLAB at DESY, Germany

Keywords: in situ XRD/XAS; high-pressure; flexible; sample cell design; in situ X-ray experiments; hardware.

Supporting information: this article has supporting information at journals.iucr.org/s

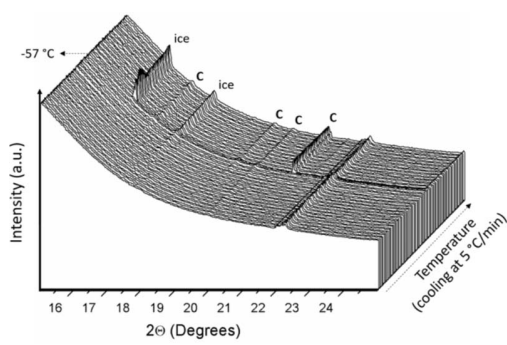

C 2018 International Union of Crystallography

\section{Low-cost disposable high-pressure setup for in situ X-ray experiments}

\author{
Maarten Houlleberghs, Johan A. Martens and Eric Breynaert* \\ Center for Surface Chemistry and Catalysis (COK), KU Leuven, Celestijnenlaan 200f, Box 2461, Heverlee 3001, \\ Belgium. *Correspondence e-mail: eric.breynaert@kuleuven.be
}

A low-cost, flexible and fast method to create disposable sample cells suitable for in situ catalytic or material synthesis studies based on standard quartz capillaries, heat-shrinkable tubing and standard Swagelok components is described.

\section{Introduction}

In situ X-ray diffraction or X-ray absorption spectroscopy measurements at elevated pressure very often rely on dedicated sample environments to meet requirements such as heat, pressure, temperature and chemical resistance in combination with suitable optical properties (Itié et al., 2015; Hansen et al., 2015; Portale et al., 2013). Many of these environments rely on the use of quartz capillaries as they exhibit excellent chemical, thermal and optical properties for many experiments. Connecting these capillaries to Swagelok tubing by means of a temperature, pressure and chemically resistant seal enables their use in static or flow systems under variable gas pressures (Martis et al., 2014; Norby, 2006). Existing setups use twocomponent Loctite glue or quick-setting epoxy resin to glue the capillary in a custom-made socket, allowing to pressurize, for example, 0.7/0.5 mm (outer/inner diameter) quartz capillaries up to 135 bar (Hansen et al., 2015; Brunelli \& Fitch, 2003; Llewellyn et al., 2009). Unfortunately, preparation and application of the adhesive sealant are not evident and the final assembly can be laborious (Jensen et al., 2010).

\section{Sample cell design}

The proposed setup circumvents the aforementioned difficulties by using a piece of heat-shrink tubing to connect the capillary to (standard) Swagelok components with a fast, chemical- and heat-resistant seal. The general procedure is illustrated in Fig. 1 for a $1 \mathrm{~mm}$ quartz capillary (Hilgenberg, Germany). The option to re-use Swagelok parts significantly lowers the marginal cost of the setup, providing an affordable method to carry out in situ X-ray experiments on pressurized samples. The cross-linked nature of the polyolefins forming the heat-shrink tubing provides good chemical and mechanical resistance and renders this setup suitable for demanding (catalytic) experiments (Beveridge \& Sabiston, 1987).

Applicability of the setup for in situ high-pressure experimentation has been showcased by monitoring $\mathrm{CH}_{4}$ hydrate formation in the pores of a hydrated hydrophobic silica material at 40 bar $\mathrm{CH}_{4}$ and $-57^{\circ} \mathrm{C}$ by wide-angle X-ray scattering (WAXS) (Fig. 2) at the Dutch-Belgian Beamline (European Synchrotron Radiation Facility, Grenoble, France) 

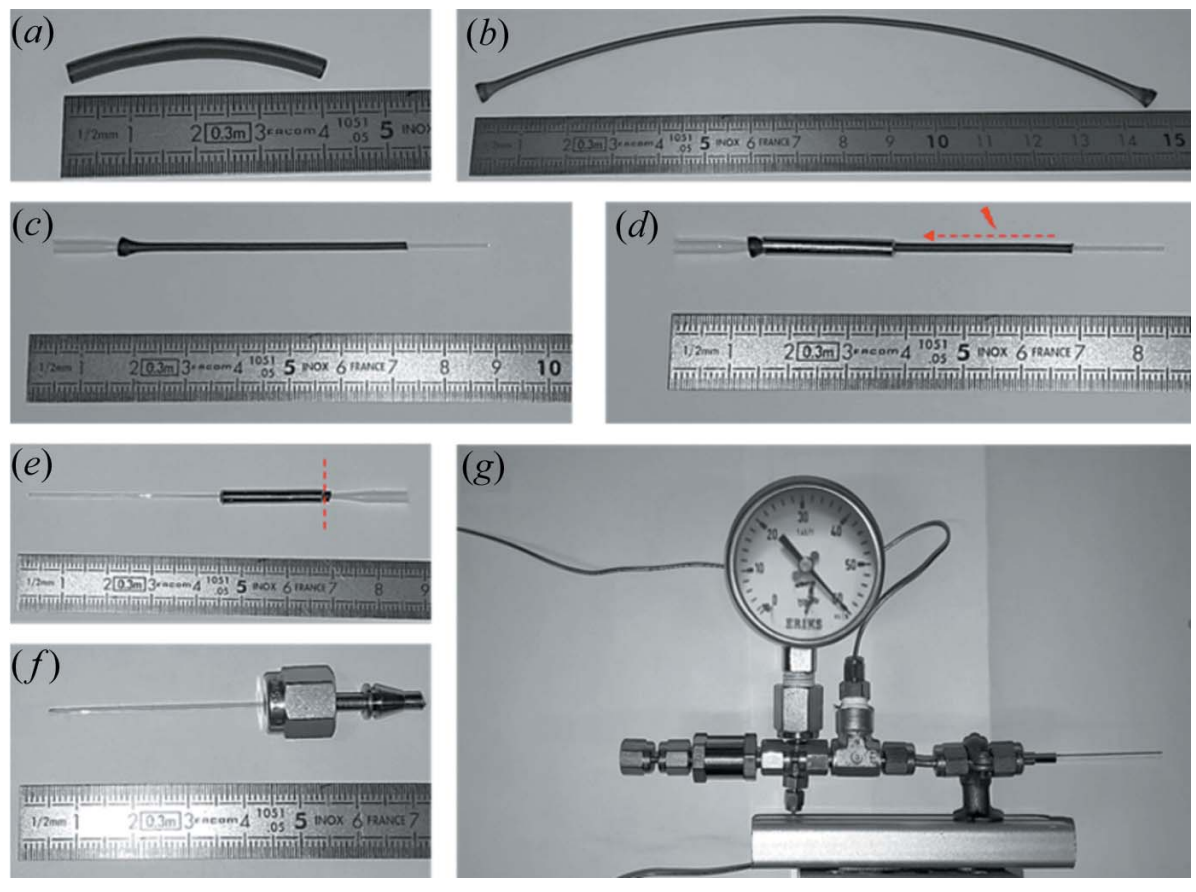

Figure 1

(a)-(b) A small piece of heat-shrink tubing of size 2.4/1.2 $\mathrm{mm}$ (inside diameter before/after heating) is manually stretched to \pm 4 times its initial length, $(c)$ cut into $\pm 5 \mathrm{~cm}$ segments and slid over the capillary. $(d)$ In the next step, a $\pm 2 \mathrm{~cm}$ piece of standard Swagelok tubing (which has been deburred on the outside and the inside) with an outer diameter of $1 / 8$ inch $(=3.175 \mathrm{~mm})$ is slid over the covered capillary. $(d)-(e)$ The heat-shrink tube is then slowly heated from the bottom up (towards the open end of the capillary) with a heat gun (first at 100 and then $350^{\circ} \mathrm{C}$ ). For the setup to work properly, it is crucial to use heat-shrink tubing shrinking lengthwise along the capillary towards the inside of the Swagelok tube after the initial stretch. The best results were obtained with $2.4 / 1.2 \mathrm{~mm}$ heat-shrink tubing (product code LSTT-R-2.4-0) manufactured by TE Connectivity (part of the Raychem group, USA). The shrinking procedure is exemplified in a video available in the supporting information (Video S1). (e) Any residual heat-shrink tubing sticking out of the Swagelok tube after shrinkage is removed with a razor blade. The open end of the capillary is then carefully cut at the Swagelok tube, preferably with a ceramic blade to prevent the formation of micro-fractures along the capillary wall. $(f)$ A set of 1/8-inch Swagelok nuts and ferrules connects the capillary to the Swagelok parts and $(g)$ allows pressures up to 65 bar in the case of $1 \mathrm{~mm}$ quartz capillaries. A second video showcasing pressurization of the newly developed capillary setup with 60 bar of $\mathrm{N}_{2}$ is also provided in the supporting information (Video S2).

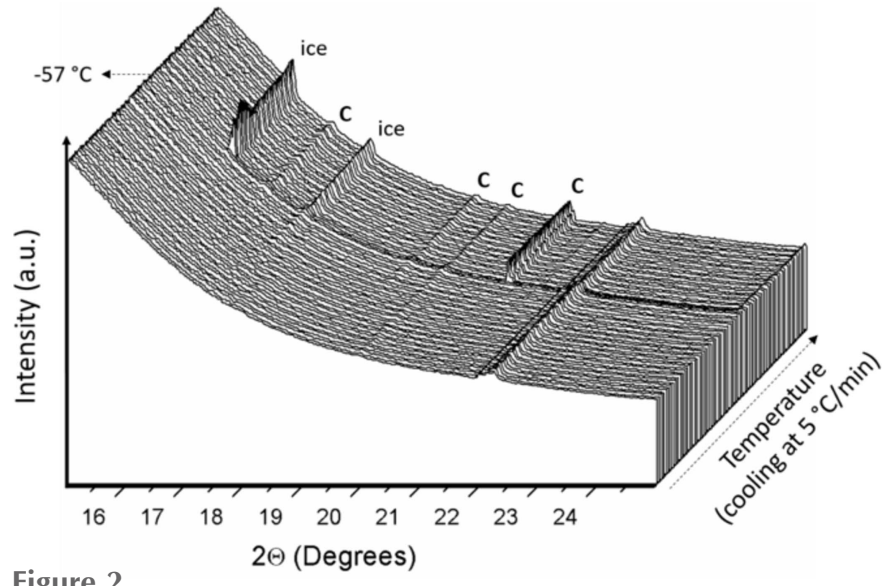

Figure 2

WAXS diffraction pattern showing the formation of the $\mathrm{CH}_{4}$ clathrate hydrate inside the pores of a hydrated hydrophobic reverse-phase silica material. Reflections that are characteristic of $\mathrm{CH}_{4}$ hydrate structures are denoted by ' $\mathrm{C}$ ', whereas reflections attributed to the simultaneous formation of hexagonal ice are indicated with 'ice'. The onset of clathrate formation is clearly visible at $-57^{\circ} \mathrm{C}$ and is accompanied by a decrease in $\mathrm{CH}_{4}$ pressure of \pm 0.5 bar.
(Borsboom et al., 1998). These ice-like clathrate materials are typically formed at high (gas) pressures and low temperatures as a result of the favourable van der Waals interactions between non-polar guest molecules such as $\mathrm{CH}_{4}$ and the surrounding water molecules (Casco et al., 2015).

\section{Acknowledgements}

The authors would like to extend their gratitude to the team of the DUBBLE beamline at the ESRF, in particular Dr Daniel Hermida Merino, Dr Allessandro Longo and $\mathrm{Mr}$ Florian Ledrappier for their support.

\section{Funding information}

MH and EB acknowledge FWO for an SB PhD fellowship and a 'Krediet aan navorsers' (1.5.061.18 N), respectively. JAM acknowledges the Flemish Government for long-term structural funding (Methusalem), the Research Foundation Flanders (FWO) and the Belgian government for Interuniversity Attraction Poles (IAP).

\section{References}

Beveridge, C. \& Sabiston, A. (1987). Mater. Des. 8, 263-268.

Borsboom, M., Bras, W., Cerjak, I., Detollenaere, D., Glastra van Loon, D., Goedtkindt, P., Konijnenburg, M., Lassing, P., Levine, Y. K., Munneke, B., Oversluizen, M., van Tol, R. \& Vlieg, E. (1998). J. Synchrotron Rad. 5, 518-520.

Brunelli, M. \& Fitch, A. N. (2003). J. Synchrotron Rad. 10, 337-339. Casco, M. E., Silvestre-Albero, J., Ramírez-Cuesta, A. J., Rey, F., Jordá, J. L., Bansode, A., Urakawa, A., Peral, I., MartínezEscandell, M., Kaneko, K. \& Rodríguez-Reinoso, F. (2015). Nat. Commun. 6, 6432.

Hansen, B. R. S., Møller, K. T., Paskevicius, M., Dippel, A.-C., Walter, P., Webb, C. J., Pistidda, C., Bergemann, N., Dornheim, M., Klassen, T., Jørgensen, J.-E. \& Jensen, T. R. (2015). J. Appl. Cryst. 48, 1234-1241.

Itié, J. P., Girard, E., Guignot, N., Le Godec, Y. \& Mezouar, M. (2015). J. Phys. D Appl. Phys. 48, 504007.

Jensen, T. R., Nielsen, T. K., Filinchuk, Y., Jørgensen, J.-E., Cerenius, Y., Gray, E. M. \& Webb, C. J. (2010). J. Appl. Cryst. 43, 1456-1463.

Llewellyn, P. L., Horcajada, P., Maurin, G., Devic, T., Rosenbach, N., Bourrelly, S., Serre, C., Vincent, D., Loera-Serna, S., Filinchuk, Y. \& Férey, G. (2009). J. Am. Chem. Soc. 131, 13002-13008.

Martis, V., Beale, A. M., Detollenaere, D., Banerjee, D., Moroni, M., Gosselin, F. \& Bras, W. (2014). J. Synchrotron Rad. 21, 462-463.

Norby, P. (2006). Curr. Opin. Colloid Interface Sci. 11, 118-125.

Portale, G., Cavallo, D., Alfonso, G. C., Hermida-Merino, D., van Drongelen, M., Balzano, L., Peters, G. W. M., Goossens, J. G. P. \& Bras, W. (2013). J. Appl. Cryst. 46, 1681-1689. 